\title{
Effect of Moisture Content on Shear Strength of the Stabilized Soil
}

\author{
M. Thillai Backiam \\ Assistant Professor, \\ Department of Civil Engineering \\ Velammal Engineering College, \\ Chennai, Tamilnadu, India.
}

\author{
B. Jeyanth \\ Assistant Professor, \\ Department of Civil Engineering \\ Velammal Engineering College, \\ Chennai, Tamilnadu, India.
}

\begin{abstract}
Soil stabilization could be a technique of modifying the properties of a soil to enhance its Engineering performance and used for a spread of engineering works. In recent years soil stabilization is the major drawback for Civil Engineers, either for construction of road or for increasing the shear strength of the soil. In areas adjacent to water bodies, the soil gets saturated that decrease the shear strength of soil. This research work was allotted with a view to study the result of soil moisture content on the soil by utilizing GGBS (Ground granulated furnace Slag). The virgin clay soil was tested for its index properties, Compaction characteristics and additionally the shear strength was also determined. The stabilization of the clay is made by adding the GGBS with varying proportion. The stabilized soil with completely different moisture content was tested for the shear strength characteristics and their results were compared with the virgin soil to seek out the consequences of moisture content on artificial improvement of shear strength of soil.
\end{abstract}

Keywords- Soil Stabilization, Shear Strength, Moisture Content, GGBS.

\section{INTRODUCTION}

Soil stabilization is a technique that to enhance to boost the index and engineering properties of an expansive soil. Recently soil is stabilized by using chemicals and industrial waste effluent like ash, ground granulated blast furnace slag (GGBS), iron slag and a few natural fibres [1]. To enhance the soil properties, the soil is stabilized by adding GGBS and also the effect of moisture content in the shear strength were studied [7].

GGBS (Ground coarse Blast Slag) is that the waste obtained from steel manufacturing process. From the previous studies, it is clear that the GGBS induces the strength of cement and is extensively used as cement additives [2]. This can be implemented in the soil for stabilization. Moisture content in soil is a crucial property that is greatly affects the strength and structural stability of the soil grains [3]. Especially the shear strength of fine grained soil is highly full of soil moisture content [10]. In case of laboratory, the shear strength experiment was conducted in the soil sample with field condition [6]. However in the expansive soil shear strength is affected by seasonal moisture content variation that leads to failure in future [4]. Thus it's planned during this the study to research the result of water content on shear strength of the stable soil.

\section{MATERIALS}

A. Soil

Soil sample were collected from Padappai, Kanchipuram district which is located $15 \mathrm{kms}$ from Tambaram, Chennai. The site is located off Vandalur Walajabad high road. The geography of this area, where the soil obtained is clayey in nature located nearby to a water body where constructions of apartments are taking place. Undisturbed soil sample were taken at 5 feet in depth.

\section{B. $G G B S$}

GGBS is a non-metallic product consisting essentially of silicates and aluminates of calcium and other bases. The specific gravity of GGBS used in this project is 2.65 .

\section{METHODOLOGY}

The soil sample collected from the site was tested for determination of its index properties, plastic limit and specific gravity. The soil sample is also tested for its compaction behavior by proctor test and shear strength by Unconfined Compression test. The soil sample is then stabilized with GGBS by varying it mix proportions. The stabilized soil was also tested for the shear strength characteristics with different moisture content. Abbreviations and Acronyms

\section{RESULT \& DISCUSSION}

After the text edit has been completed, the paper is ready for the template. Duplicate the template file by using the Save As command, and use the naming convention prescribed by your conference for the name of your paper. In this newly created file, highlight all of the contents and import your prepared text file. You are now ready to style your paper; use the scroll down window on the left of the MS Word Formatting toolbar.

\section{A. Properties of soil sample}

The soil sample was tested for its consistency limit. The liquid limit, plastic limit and shrinkage limit is found to be $45 \%$ a $33 \%$ and $26 \%$ respectively. Thus the plasticity index of the soil sample is calculated as $12 \%$. By referring the A-line chart, the clay soil is classified as Medium Plastic nature (CI). The Specific gravity of the soil is 2.2. The Standard Proctor compaction test on clay resulted that their Maximum Dry Density (MDD) and Optimum Moisture Content (OMC) as $1.95 \mathrm{~g} / \mathrm{cc}$ and $20 \%$ respectively. The Unconfined Compressive Strength $\left(\mathrm{q}_{\mathrm{u}}\right)$ of the virgin soil is found to be $86.13 \mathrm{kN} / \mathrm{m}^{2}$ and the Undrained Cohesion $(\mathrm{Cu})$ of the sample is $43 \mathrm{kN} / \mathrm{m}^{2}$. 


\section{B. Effect of Stabilization on Index Properties}

The changes in the index properties of soil sample due to stabilization of soil with different percentage of GGBS are presented in table 1

Table 1 Effect of Stabilization on index properties

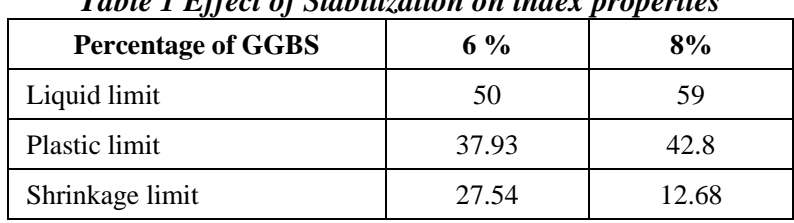

The index properties of soil test results conducted on clay soil treated by GGBS along with virgin soil are compared graphically in Fig 1, Fig. 2 and Fig. 3 respectively.

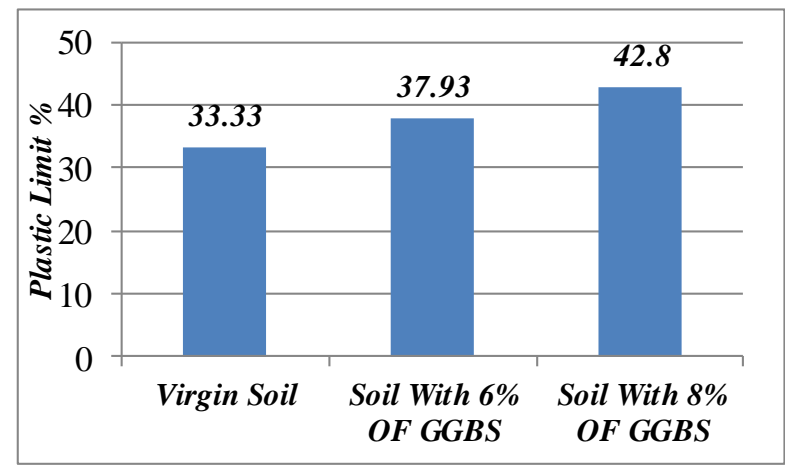

Fig. 1 Comparison of Liquid Limits of soil stabilized with GGBS

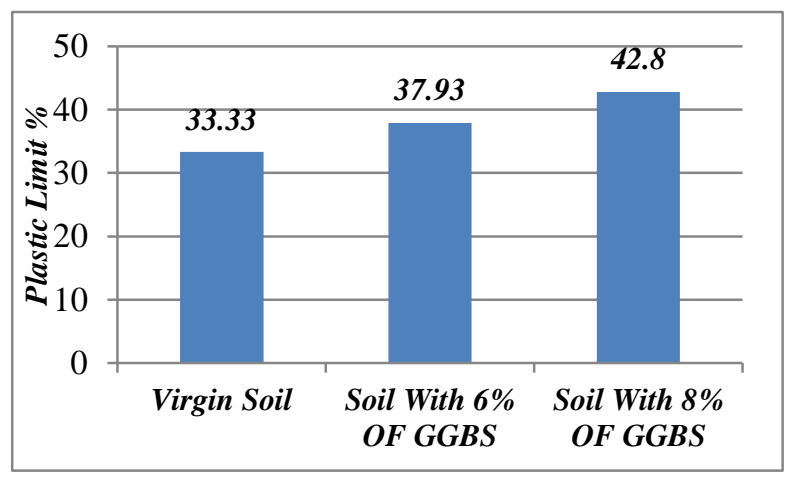

Fig. 2 Comparison of Plastic Limits of soil stabilized with GGBS

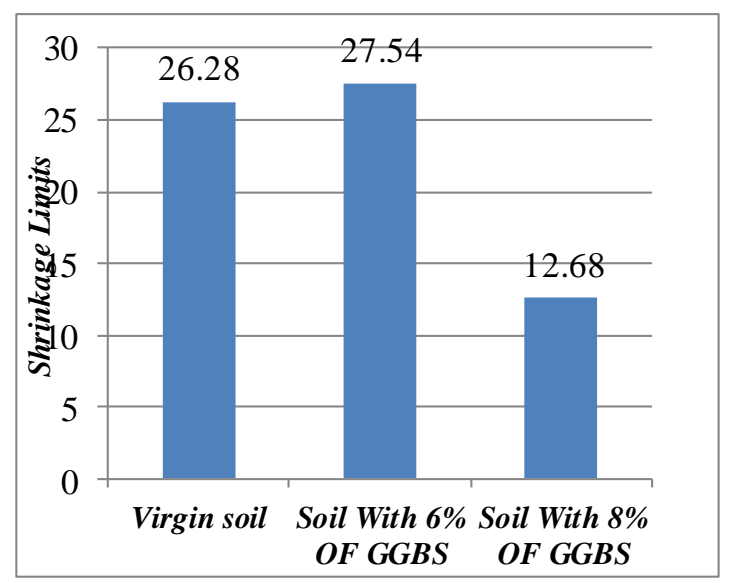

Fig. 3 Comparison of shrinkage Limit of soil stabilized with GGBS
It was observed that the increase in the percentages of GGBS is leads to increase in the liquid and plastic limit of soil. In case of shrinkage limit for soil stabilized with $8 \%$ of GGBS decreases the value as compared to soil stabilized with $6 \%$ of GGBS.

\section{Effect of moisture content on shear Strength Parameters of stabilized soil}

The unconfined compression test was conducted for stabilized soil with various the percentage of moisture content and the result are presented in table II. The stress strain curve for virgin soil and stabilized soil with various percentage of moisture content are represented in Fig IV, Fig V, Fig VI and Fig VII respectively and also the graphical comparison of soil shear strength with different moisture content are represented in Fig. VII.

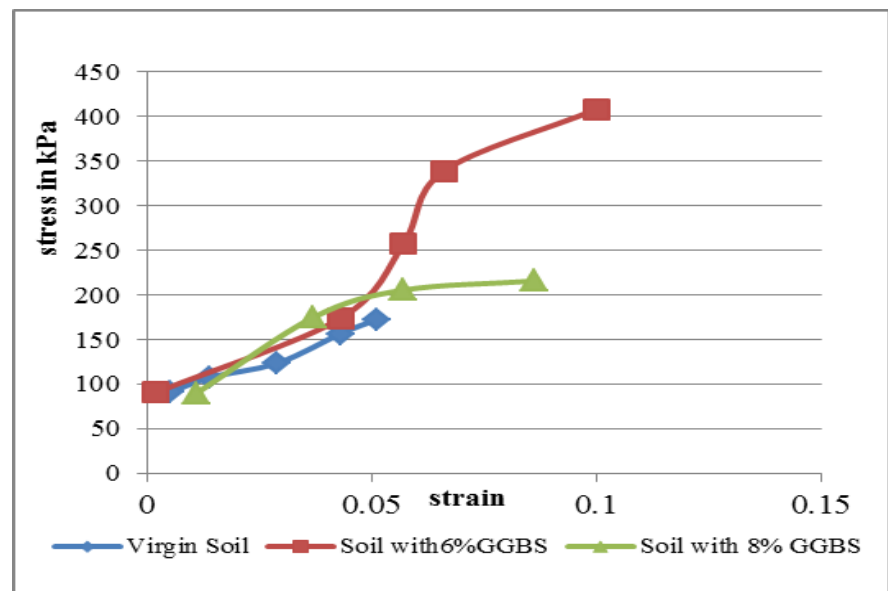

Fig. 4 Stress strain curve for soil samples with 20 percentage moisture content.

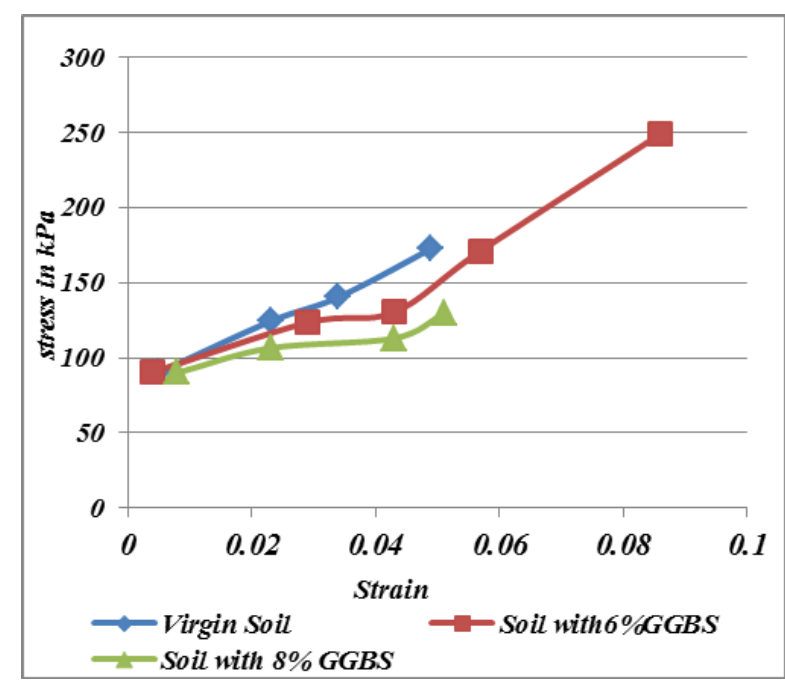

Fig. 5 Stress strain curve for soil samples with 22 percentage moisture content. 


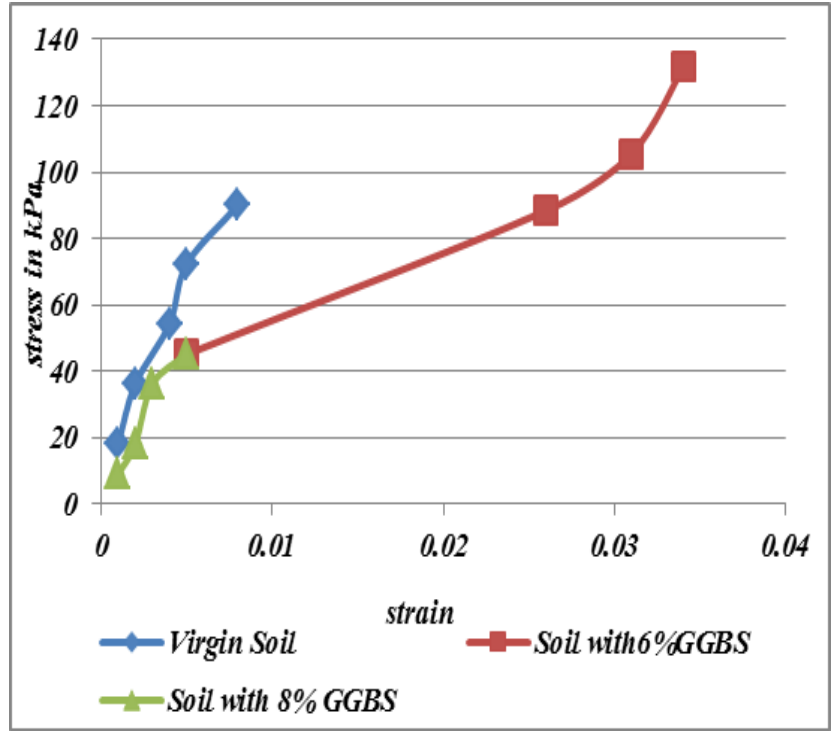

Fig.6 Stress strain curve for soil samples with 24 percentage moisture content.

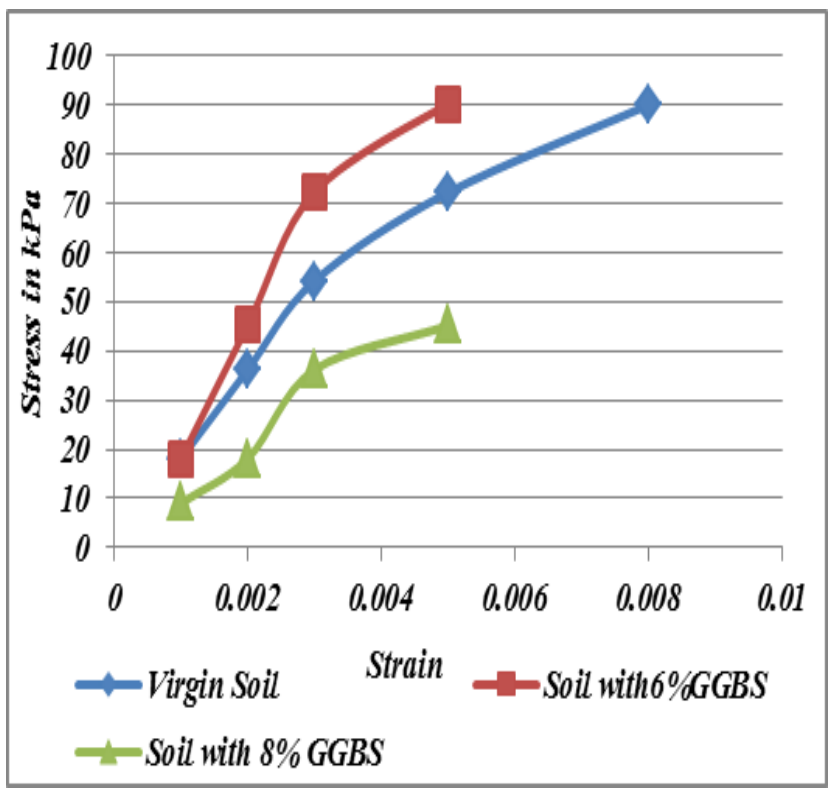

Fig. 7 Stress strain curve for soil samples with 26 percentage moisture content

Table 2 Effect of moisture content on shear Strength Parameters of stabilized soil

\begin{tabular}{|c|c|c|c|}
\hline \multirow{2}{*}{$\begin{array}{c}\text { Moisture } \\
\text { content } \\
\text { percentage }\end{array}$} & \multicolumn{3}{|c|}{ Soil Shear Strength $\mathrm{kN} / \mathrm{m}^{2}$} \\
\hline & $\begin{array}{c}\text { Virgin } \\
\text { soil }\end{array}$ & $\begin{array}{c}\text { Soil stabilized with } \\
6 \% \text { GGBS }\end{array}$ & $\begin{array}{c}\text { Soil stabilized with } \\
8 \% \text { GGBS }\end{array}$ \\
\hline 20 & 86.13 & 204.2 & 117.6 \\
\hline 22 & 86.32 & 124.44 & 84.32 \\
\hline 24 & 45.02 & 65.77 & 22.57 \\
\hline 26 & 36.13 & 45.15 & 22.57 \\
\hline
\end{tabular}

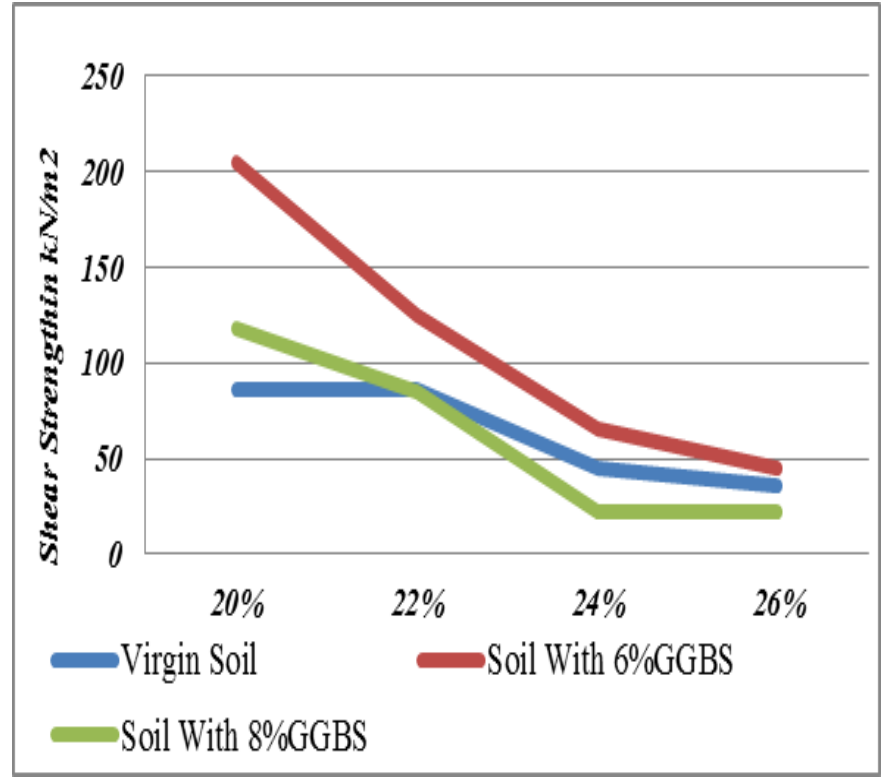

Fig. 8 Comparison of Shear strength of stabilized soil with different moisture content

It was found that the shear strength of soil goes on decreasing with increase in moisture content, both in the case of virgin soil alone and soil Stabilized with GBBS.

\section{CONCLUSIONS}

The soil is stabilized with GGBS at $6 \%$ and $8 \%$. The index property test, compaction test and unconfined compression test were carried out on virgin soil and stabilized soil. Also the effects of moisture content on shear strength characteristics of stabilized soil are tested. Based on the experimental test result the following conclusion were made,

The liquid limit and plastic limit was improved with increasing the percentage of GGBS. In case of shrinkage limit, the soil stabilized with $6 \%$ of GGBS shows the improvement as compared to soil stabilized with $8 \%$ of GGBS.

The stabilization soil with $6 \%$ of GGBS shown an improvement in strength and Shear strength of soil goes on decreasing with increase in moisture content, both in the case of virgin soil alone and soil Stabilized with GGBS.

\section{REFERENCES}

[1] Adams Joe M, A. Maria Rajesh,(2015), "Soil Stabilization Using Industrial Waste and Lime", International Journal of Scientific Research Engineering \& Technology, Volume 4, Issue 7, pp.799805

[2] Ashish Kumar Pathak, Dr.V.Pandey Krishna Murari J.P.Singh(2014) "Soil Stabilisation Using Ground Granulated Blast Furnace Slag", Journal of Engineering Research and Applications, Vol. 4, Issue 5( Version 2), pp.164-171

[3] Ferre, G. C., Topp, P. A., (2002), "The Soil Solution Phase. In Methods of Soil Analysis, Part 4 Physical Mehods", Madison, Wisconsin, USA: Soil Science Society of America, Inc., 1663.

[4] Hendron.A.J, Patton.F.D, (1987), "The Vaiont slide - a geotechnical analysis based on new geologic observations of the failure surface", Engineering Geology, 24, 1: 475-491.

[5] Kamalesh Kumar, Anmol Verma, Aman Aggarwal,( 2013), "Moisture Content Effect on Sliding Shear Test Parameters in Woven Geotextile Reinforced Pilani Soil", International Journal of Engineering Science Invention, Volume 2 Issue 8,PP.10-15 
[6] Kristyna Blahova, Lenka Sevelova, Pavla Pilarova,(2013), "Influence of water content on the shear strength parameters of clayey soil in relation to stability analysis of a hillside in brno region", Acta Universitatis Agriculturae Et Silviculturae Mendelianae Brunensis Volume LXI 174 Number 6

[7] Laxmikant Yadu1, R.K. Tripathi,(2013) "Stabilization of Soft Soil With Granulated Blast Furnace Slag And Fly Ash", International Journal of Research in Engineering and Technology. Volume: 02 Issue: 02 , pp.115-118

[8] Manjunath, Himanshu Shekhar K.V, Manish Kumar, Prem Kumar and Rakesh Kumar,( 2012), "Stabilization of Black Cotton Soil Using Ground Granulated Blast Furnace Slag", Proceedings of International Conference on Advances in Architecture and Civil Engineering, Vol. 1.

[9] Oormila.T.R \& T.V.Preethi,(2014),"Effect of Stabilization Using Flyash and GGBS in Soil Characteristics", International Journal of Engineering Trends and Technology Volume 11 Number 6.

[10] Rohit Ghosh., (2013), "Effect of soil moisture in the analysis of undrained shear strength of compacted clayey soil", Journal of Civil Engineering and Construction Technology Vol. 4(1), pp. 23-31. 